\title{
Study of Simulation Comparing WiMAX Network Fixed and Mobile using OPNET Modeler
}

\author{
Awan Nahel Mahmood \\ Assistant Lecturer Department of Electronics \& Collage Electronics Engineering \\ Nineveh University, Mosul, Iraq
}

\begin{abstract}
In the WiMAX (Worldwide interoperability for Microwave Access) the standard based on two modes: fixed and mobile, this provides wireless broadband to fixed and mobile terminals. WiMAX is an enhanced approach of wireless broadband. This paper focus on comparing between two networking approach Fixed and mobile terminal considering a video and voice over IP(VOIP) technology. It is using signal video with VOIP. to study similarity and difference in performance delay, load and Throughput in both fixed and mobile WiMAX.
\end{abstract}

\section{Keywords}

WiMAX, Delay, Load, Throughput, OPNET.

\section{INTRODUCTION}

WiMAX standards defines formal specification to provide wireless broadband to fixed and mobile terminals. WiMAX operates on two frequencies range 10-66 GHZ(licensed frequency band) for line of sight (LOS) as well as 2-11 GHZ (unlicensed frequency band) Non-line of sight operation. WiMAX Network growth uses OFDM (orthogonal frequency division multiplexing) which makes transmission more resisting to signals interference [1].

\subsection{IEEE 802.16d-2004 - Fixed WiMAX}

The IEEE.16 standard owns High development in different stages during different part of technology. Fixed WiMAX on operational frequencies spanning from 10 to $66 \mathrm{GHz}$, the Physical is based on SC modulation. For (NLOS) propagation conditions at frequencies below $11 \mathrm{GHz}$ the connection using (SC.OFDM) Single-carrier is a frequencydivision multiple access scheme. The modulation in early of WiMAX was based on the Wireless Metropolitan Area Network (Wireless MAN),Therefore the fixed WiMAX does not support mobility [2].

\subsection{IEEE 802.16e-2005 - Mobile WiMAX}

WiMAX continues the developments on different stages to support the mobility. it supports subscriber stations(SCs) moving at vehicular speeds, thereby Specification it introduced a system for combined fixed and mobile broadband Wireless Access(BWA), the mobility services also known as mobile [2].WiMAX System used 4G (Fourth generation)system to solve the problems of 3G (Three generation) systems. $4 \mathrm{G}$ designed to give new services like high-quality voice to high-definition video to high -data-rate wireless channels. [3] Video conferencing contains the transfer of audio and video between two users point to point (PTP) or among multiple users multiple users to multiple users (MTM). The video is encoded as a series of video frames, with frame rates ranging from 8 frames per second (fps) for low-bandwidth, video with low quality, to $30 \mathrm{fps}$ or higher for video with high-quality. The video is compressed by using lossy compression codes like MPEG-4 or H.264 to save bandwidth [4]. VoIP voice over IP may deliver voice communications and multimedia sessions over Internet Protocol (IP). This process includes fragmentation defragmentation of voice, isolation of jam signals and then compression the voice signal with the use of compression/decompression (coding/ encoding) algorithms. [5] The communication basic role in WiMAX network consists of one Base Station (BS) and one or more Subscribers Station (SS) Fig. 1 shows . In IEEE 802.16 specifies the following modes of development architectures :

Point-To-Point: A connection between one BS and one SS.

Point-to-Multipoint: A connection between one BS and multiple SS nodes. The BS always coordinates the uplink and downlink transmission.

Mesh: Subscriber Station(SS) can communicate with each other without the coordination of a Base Station(BS). Both BS and SS are stationary while clients connected to SS can be mobile. [6]

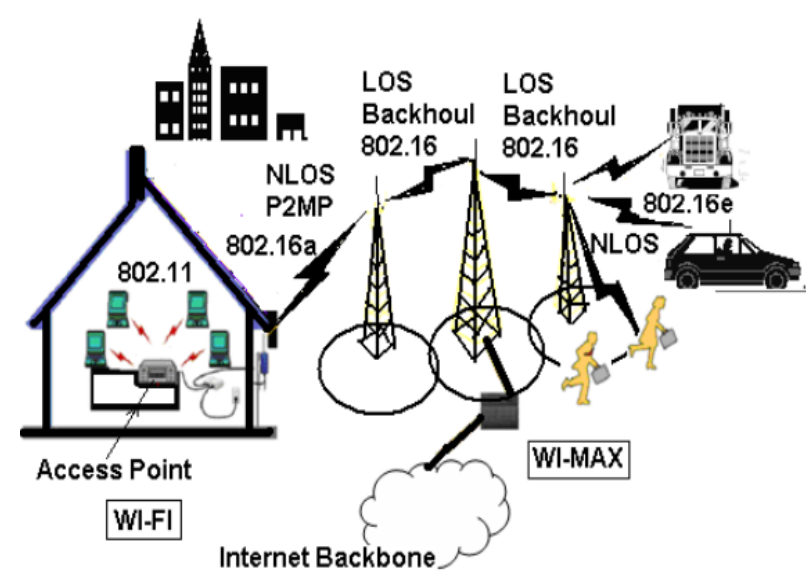

Fig.1 Point to Point, Point to Multipoint and Mesh [7].

Quality of Service in WiMAX (QoS):

The IEEE802.16d standard provides of (QoS) by using applications in different methods for example video, VOIP and other types. The quality of service in IEEE 802.16 is divided in to five classes: [8]

1. UGS (Unsolicited Grant Service):designed to provide constant bit rate (CBR) services, such as VoIP without silence suppression.

2. Real-Time Polling Services (rtPS): designed to provide real-time services that generates variable data size packets, such as MPEG video or VoIP with silence suppression.

3. Non-Real-Time Polling Services (nrtPS): designed to provide non-real-time services that requires variable size data grant burst types on a regular basis. 
4. Best Effort (BE) Services: the services are typically provided by the Internet today for web surfing.

\section{SIMULATION MODEL}

The Network consists of two WiMAX cell i.e. and two BS(base station) and number of SS (subscriber station) per cell. The parameters of SS and BS are given in configuration figures.

Each BS is connected to the IP backbone. In addition it is connected to IP cloud with connect to server to provide two types of application for example VOIP and Video in network. The channel was configured to vary according to ITU Pedestrian A multipath fading model. All scenarios running in $600 \mathrm{sec}$, and traffic configuration, all configuration in figures $2,3,4,5,6$

\begin{tabular}{|c|c|c|}
\hline \multicolumn{2}{|c|}{ Attribute } & Value \\
\hline \multicolumn{2}{|c|}{$\boxminus$ Row 0} & \\
\hline (?) & Service Class Name & Gold \\
\hline (?) & Scheduling Type & UGS \\
\hline (?) & Maximum Sustained Traffic Rate (b... & $0.5 \mathrm{Mbps}$ \\
\hline (?) & Minimum Reserved Traffic Rate (bps) & $0.5 \mathrm{Mbps}$ \\
\hline (3) & Maximum Latency (milliseconds) & 30.0 \\
\hline (?) & Maximum Traffic Burst (bytes) & 0 \\
\hline (3) & Traffic Prionity & Not Used \\
\hline (2) & Unsolicited Poll Interval (milliseconds) & Auto Calculated \\
\hline \multicolumn{2}{|r|}{ - Row 1} & \\
\hline (?) & Service Class Name & Silver \\
\hline (3) & Scheduling Type & IPS \\
\hline (?) & Maximum Sustained Traffic Rate b... & $0.5 \mathrm{Mbps}$ \\
\hline (?) & Minimum Reserved Traffic Rate (bps) & $0.5 \mathrm{Mbps}$ \\
\hline (3) & Maximum Latency (milliseconds) & 30.0 \\
\hline (3) & Maximum Traffic Burst (bytes) & 0 \\
\hline (3) & Traffic Prionity & Not Used \\
\hline (3) & Unsolicited Poll Interval (milliseconds) & Auto Calculated \\
\hline
\end{tabular}

Fig.2 WiMAX Network configuration

In Fig.2 configuration of WiMAX used two types from Quality of Service UGS and rtPS represented video and VOIP systems.

\begin{tabular}{|c|c|c|}
\hline \multicolumn{2}{|c|}{ Attribute } & Value \\
\hline \multicolumn{2}{|c|}{ (2) :"name } & Base Station_1 \\
\hline \multicolumn{3}{|c|}{ — WiMAX Parameters } \\
\hline (?) & Antenna Gain (dBi) & $15 \mathrm{dBi}$ \\
\hline (?) & + BS Parameters & $(\ldots)$ \\
\hline (3) & $\doteq$ Classifier Definitions & (...) \\
\hline (?) & MAC Address & Auto Assigned \\
\hline (?) & Maximum Transmission Power (W) & 0.5 \\
\hline (?) & PHY Profile & WirelessOFDMA $20 \mathrm{MHz}$ \\
\hline (?) & PHY Profile Type & OFDM \\
\hline (?) & PermBase & 0 \\
\hline & IP Routing Protocols & \\
\hline
\end{tabular}

\section{Fig.3 Base station configuration}

In Fig.3 configuration of base station interactive specification of application multimedia.

\begin{tabular}{|c|c|}
\hline Attribute & Value \\
\hline (3) :name & node_1 \\
\hline (3) Application Defintions & (...) \\
\hline Number of Rows & 2 \\
\hline \multicolumn{2}{|c|}{ E Video Conferencing (Light) } \\
\hline Name & Video Conferencing (Light) \\
\hline \pm Description & (...) \\
\hline \multicolumn{2}{|c|}{ - Voice over IP Call (PCM Qualthy) } \\
\hline (9) Name & Voice over IP Call (PCM Quality) \\
\hline (9) \pm Description & $(\ldots)$ \\
\hline \multicolumn{2}{|l|}{$\nexists$ MOS } \\
\hline (9) \pm Voice Encoder Schemes & All Schemes \\
\hline
\end{tabular}

Fig.4 Application configuration (Video with Voice over IP)

In this Fig.4 provided the network WiMAX of two application video and voice over IP.

\begin{tabular}{|c|c|c|}
\hline \multicolumn{2}{|c|}{ Attribute } & Value \\
\hline \multicolumn{2}{|c|}{ (?) :" name } & node-2 \\
\hline \multicolumn{2}{|c|}{ (?) - Profile Configuration } & $(\ldots)$ \\
\hline & Number of Rows & 1 \\
\hline \multicolumn{2}{|r|}{$\exists$ Multimedia User } & \\
\hline (2) & Profile Name & Multimedia User \\
\hline \multirow[t]{4}{*}{ (?) } & - Applications & (..) \\
\hline & Number of Rows & 2 \\
\hline & + Video Conferencing (Light) & $\ldots$ \\
\hline & $\doteq$ Voice over IP Call (PCM Quality) & $\ldots$ \\
\hline (?) & Operation Mode & Simultaneous \\
\hline (9) & Start Time (seconds) & uniform $(100,110)$ \\
\hline (2) & Duration (seconds) & End of Simulation \\
\hline (2) & $\Phi$ Repeatability & Once at Start Time \\
\hline
\end{tabular}

Fig.5 Profile WiMAX configuration

In Fig.5 provided applications to profile WiMAX .

\begin{tabular}{|c|c|c|}
\hline & WiMAX Parameters & \\
\hline & Applications & \\
\hline & Ð Application: ACE Tier Configuration & Unspecified \\
\hline ?) & Ð Application: Destination Preferences & None \\
\hline (?) & Ð Application: Multicasting Specification & None \\
\hline (3) & Ð Application: RSVP Parameters & None \\
\hline (?) & Application: Segment Size & 64,000 \\
\hline (2) & Ð Application: Source Preferences & None \\
\hline (2) & - Application: Supported Profiles & (...) \\
\hline & Number of Rows & 1 \\
\hline & $Ð$ Multimedia User & $\ldots$ \\
\hline (?) & Application: Supported Services & None \\
\hline (3) & Ð Application: Transport Protocol Specifi. & Default \\
\hline
\end{tabular}

Also (SS) application is provided with type multimedia user.

In this paper two different number of scenarios are used fixed and mobile WiMAX with increase number of(SS) subscriber station both fixed and mobile WiMAX . used 
OPNET modeler 14.5 for simulation [10].In start base station is provided with subscribe station and two type of application .

Scenario1: is shown in Fig.7 two base station (BS) connected to six(SS) Subscriber Station of fixed type.

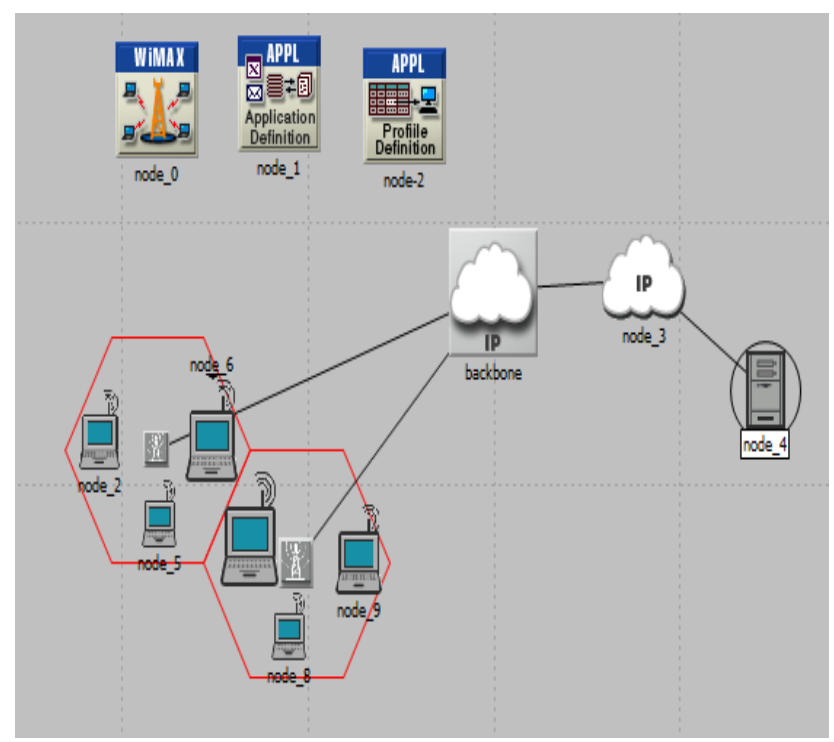

Fig.7 Scenario1

Scenario 2:shown in fig.8 used two Base station with increase number of (SSs) Subscribe station from type fixed to become 12 nodes.

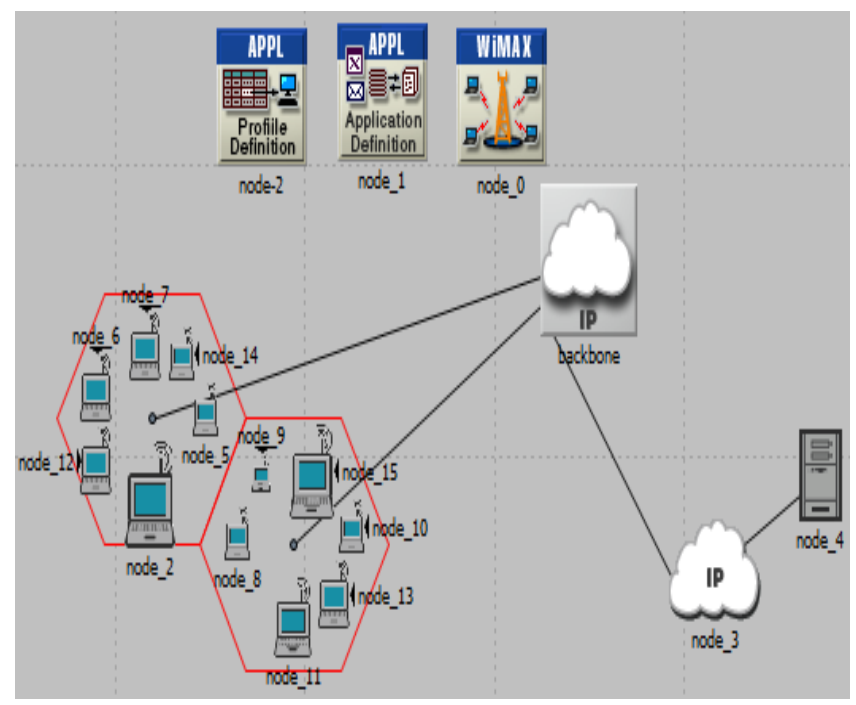

Fig.8 Scenario 2

Scenario 3:Fig.9 show two Base station is used and increase number of (SSs) Subscribe station from type fixed to become 16 nodes.

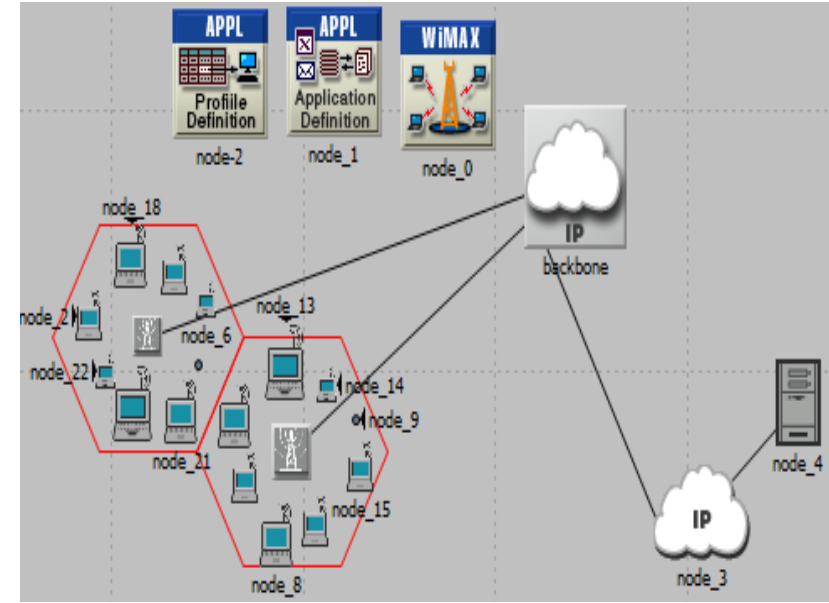

Fig.9 Scenario 3

Also in Scenario 4 two Base station is used with 16 Subscriber Station of fixed type as shown in Fig.10 .

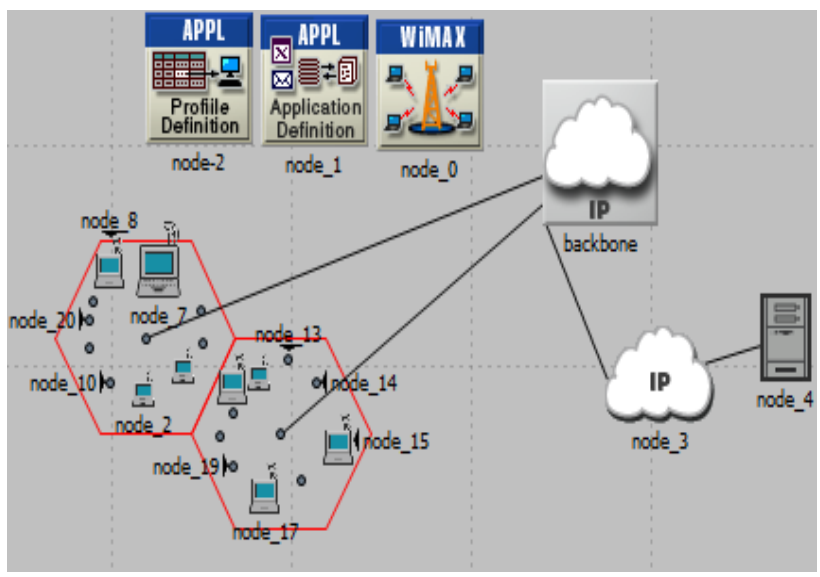

Fig.10 Scenario 4

Scenario 5: In this scenario two Base station is used but it is connected to 20 number of mobile nodes. As shown in Fig. 11

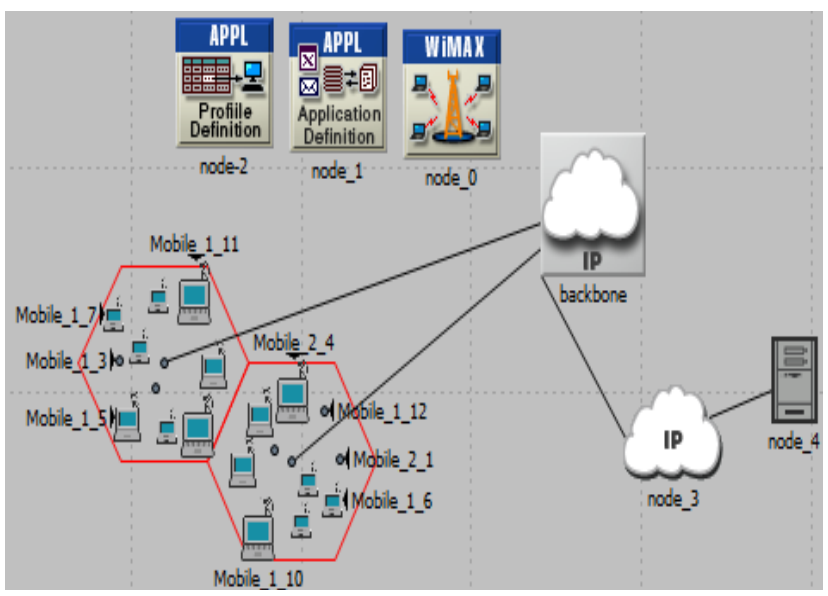

Fig.11 Scenario 5

In addition in Scenario 6 also two base station are connected to number of mobile nodes after increasing the number of mobile nodes 28 nodes this Scenario is shown in Fig12 . 


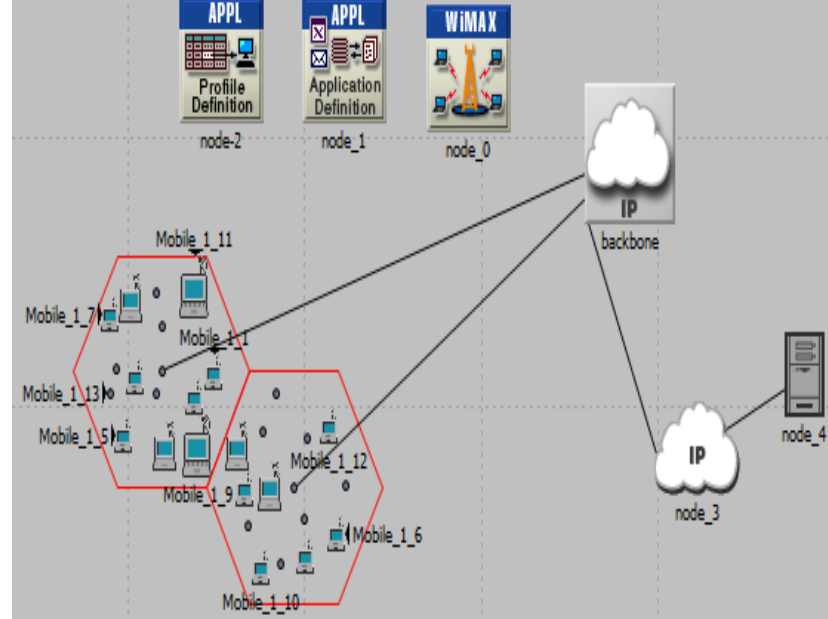

Fig.12 Scenario 6

Also in Scenario 7,8 two Base Station is used with increase number of mobile node Fig13, Fig14 .

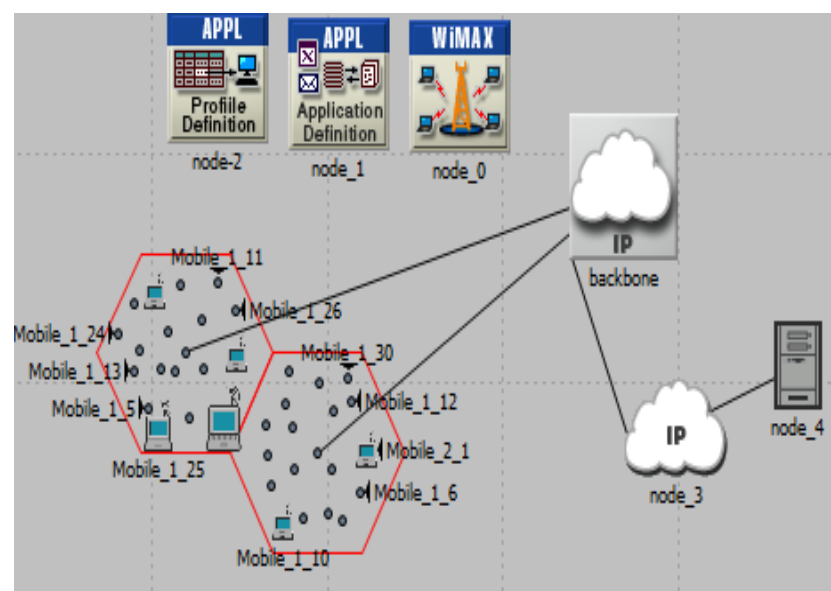

Fig.13 Scenario 7

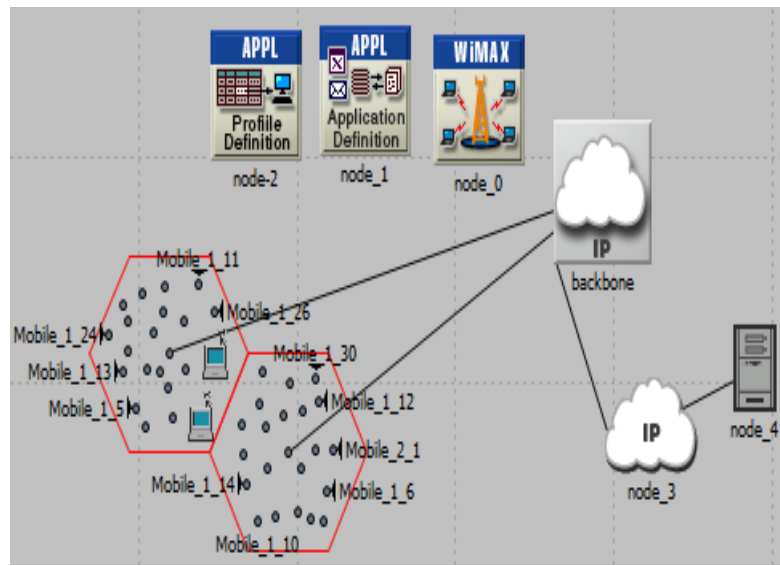

Fig.14 Scenario 8

Continues, After running each Scenario in time $600 \mathrm{Sec}$ with size constant all scenarios of cells $1 \mathrm{~m}$ to find delay to fixed WiMAX .On Opnet modeler 14.5 it is found curves of delay allocated to fixed node and to get results to find average on excel sheet shown on Fig.15 .From results that the notes average delay increase starting from value 0.270 to reach the value 2.071, linearly as the number of SSs increases causing higher delay with more SSs.

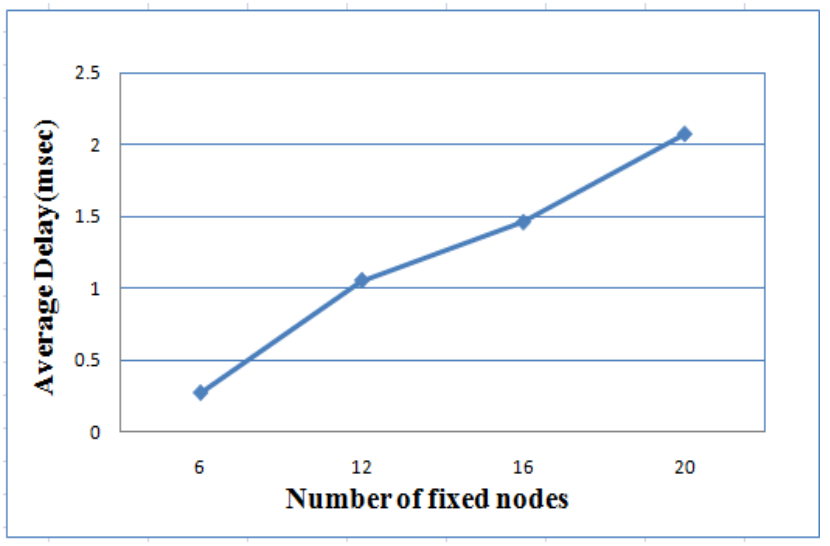

Fig.15 Average Delay in fixed nodes

Also after running each Scenario mobile nodes at same time to get curves of delay in state of mobile starting from value 0.860 to Reach value 1.729 and to get results to find average delay on excel sheet shown in fig.16. That notice there is an increase in mobile node higher from a fixed node.

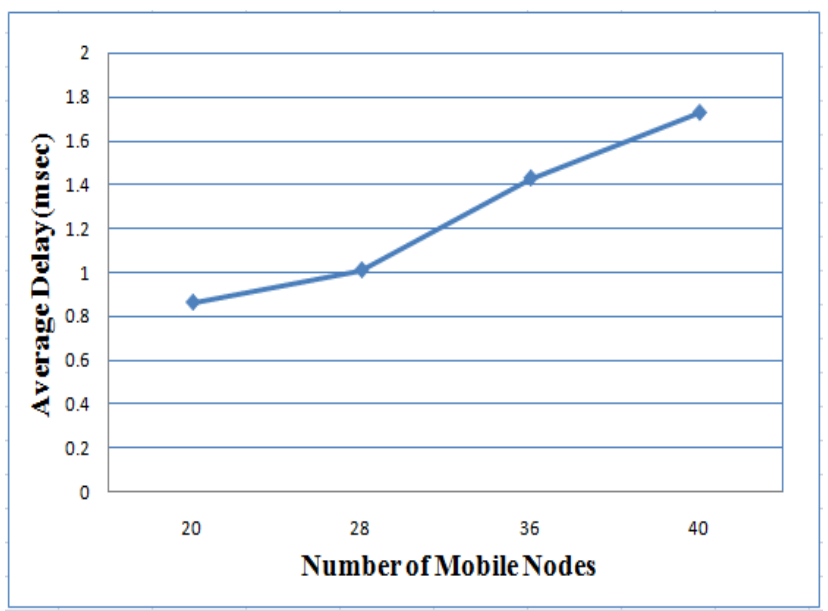

Fig.16 Average Delay in mobile nodes

Also it is noticed an increase in average delay with increase in number of nodes. But in a less values.

As well as after running to get curves of load and results from curves to find average of load allocated to fixed nodes on excel sheet shown in Fig17 . starting from value 8.647 to reach value 25.615

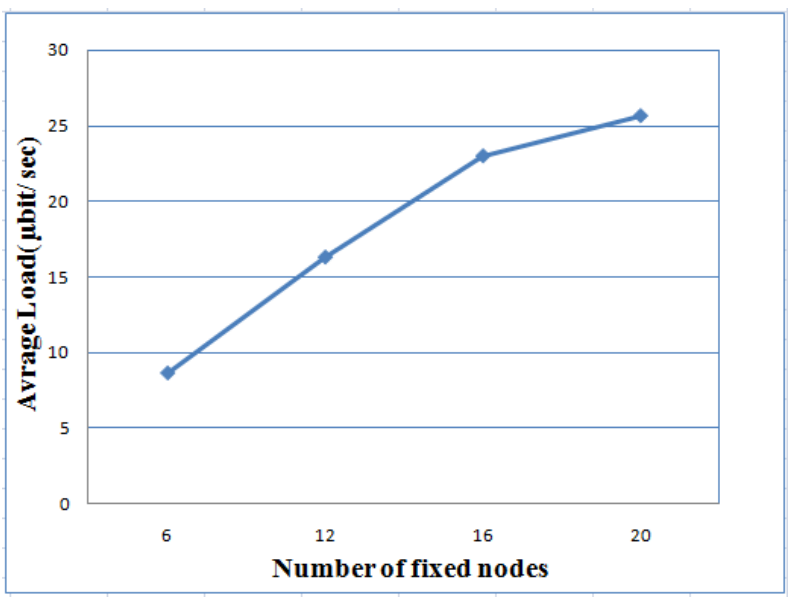

Fig.17 Average Load in fixed nodes 
Also after running the network of mobile it is get curves of load which represented results of curves to get on average of load on excel sheet shown on Fig18 .Starting from value 28.133 to reach value 50.789. As the result it is notice increase in mobile node higher from fixed node.

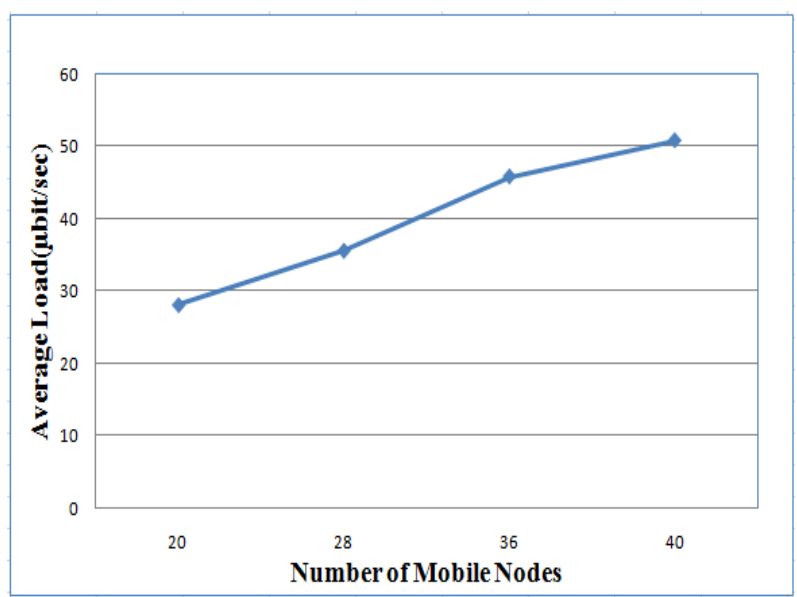

Fig.18 Average Load in mobile nodes

In addition, also after running curves of throughput is got and is converted to excel sheet to get on average Throughput to fixed nodes as shown in Fig 19 .In average throughput that different the values in state fixed node suffer an increase in values with decrease in values according amount of the data transmitter and receiver.

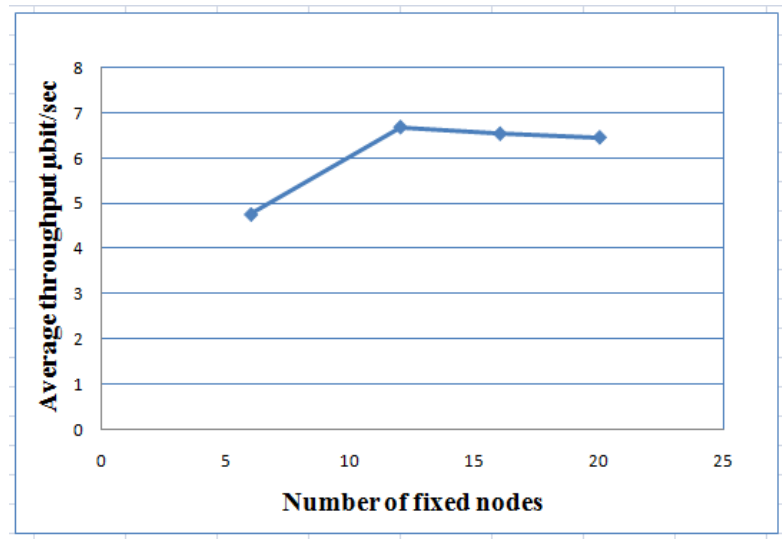

Fig.19 Average throughput in fixed nodes

In similar, in this work average of throughput is get related to mobile nodes from results on excel sheet shown on Fig.20 the values decreases to reach the limited values and starting increase according of data between base station and subscribe station.

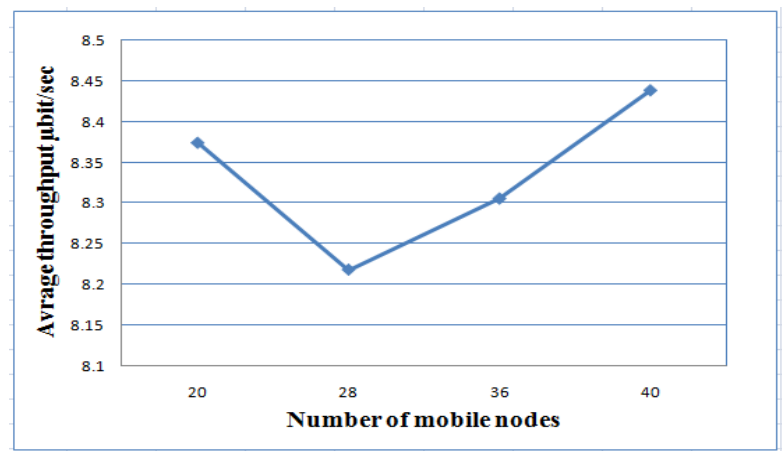

Fig.20 Average throughput in mobile nodes
In Fig.21 notice changing in application of video conferencing after running all of scenarios. notice changing in application of video.

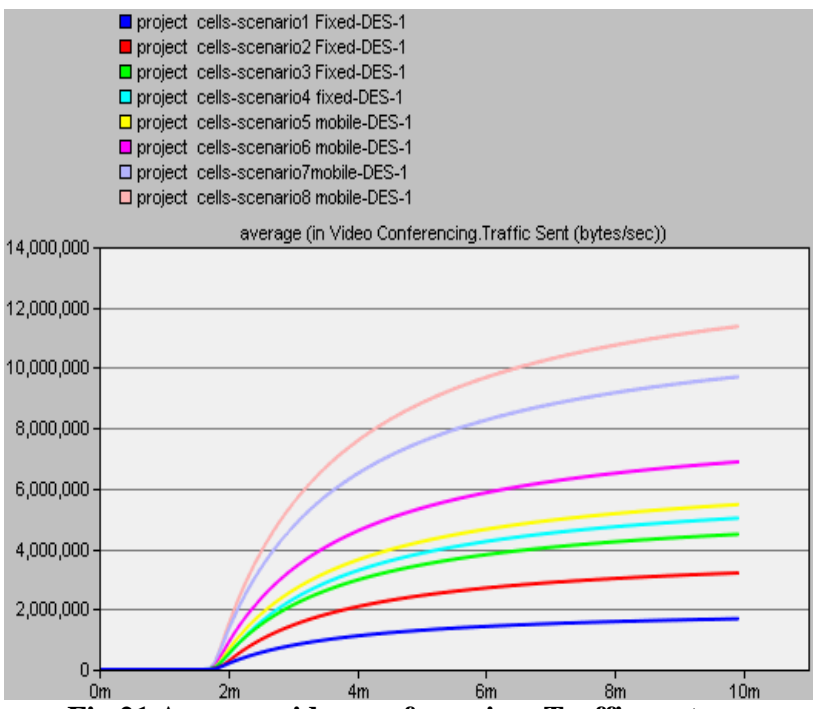

Fig.21 Average video conferencing. Traffic sent

Also in Fig.22 after running notice changing in application the voice in all scenarios. notice changing in application in traffic sent of voice

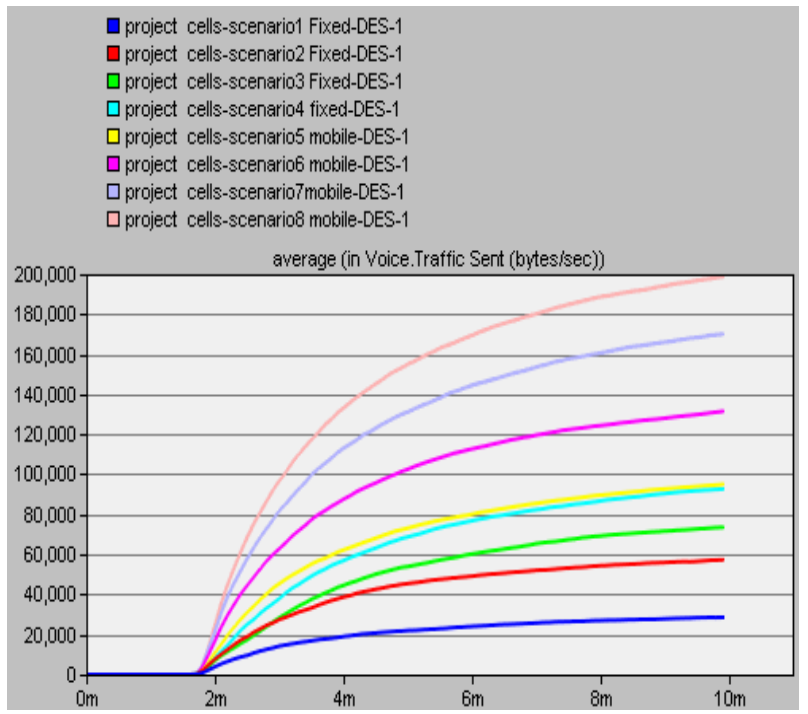

Fig.22Average voice. Traffic sent

\section{CONCLUSION}

In this paper study to find comparative analysis fixed WiMAX and mobile WiMAX through this work after providing two type form applications video and voice over IP using simulation tools OPNET 14.5. Also all results obtained from curves found that changing in level on delay ,load, throughput depending on number of nodes fixed and mobile WiMAX , Noticed from results of fixed nodes and mobile nodes increase in parameters delay, load and changing in level curves of throughput depending on increase of number of nodes that technical development in mobile or fixed WiMAX. Also notice average traffic send both video and voice when increasing number of nodes Through these statistics found two different types of works. 
The future work is study the performance analysis of mobile using the video system in mobility state as well as improve the transmission and receiver of data for the video signal and try to reduce the effect of external factors on video system, for example delay time and interference signals.

\section{REFERENCES}

[1] A. N. Naqvi, A. M. Abbas, T. A. Chouhan, "Performance Evaluation of Fixed and Mobile WiMAX Networks for UDP Traffic",International Journal of Advanced Research in Computer and Communication Engineering,Vol. 1, Issue 8, October 2012.

[2] L.Hanzo,J.Akhtman, L. Wang, M. Jiang"MIMOOFDM for LTE, Wi-Fi and WiMAX " John Wiley \& Sons Ltd, ISBN: 9780470686690 (H/B),2011.

[3] N. Bagoria, A. Garhwal , A. Sharma , "Simulation of Physical layer of WiMAX Network using OPNET Modeler", International Journal of P2P Network Trends and Technology (IJPTT). Vol. 3 Issue 4, May 2013.

[4] R. Jain, "WiMAX тм System Evaluation Methodology". V2.1 Created on July 7, 2008

[5] S. Jadhav, H. Zhang, Z. Huang, "Performance Evaluation of Quality of VoIP in WiMAX and UMTS", Parallel and Distributed Computing, Applications and Technologies (PDCAT 12th) International Conference,vol.3, pp. 375-380, 2011.

[6] A. Kumar, A. K. Garg, "Queuing Algorithm Based Quality of Service(Qos) for Scheduling Environment
Model in WiMAX Network with OPNET Modeler", Global Journal of Researches in Engineering Electronic and Electronics Engineering, ISSN:2249-3588, vol.11, issue 8, December 2011

[7] U. D. Dalal,Y. P. Kosta, "Adaptive Parameters Based Transmission Control and Optimization in Mobile WiMAX Physical Layer",WiMAX New Developments,ISBN:978-953-7619-539,December1, 2009.

[8] F. Ohrtman, "WiMAX Handbook Bulding 802.16 Wireless Networks", McGraw-HillNetworkingand Telecommunications, vol. 2, issue 5, pp. 58-67, 2005.

[9] R. K. Jha, I. Z. Bholebawa, U. Dalal , "Location Based Performance of WiMAX Network for QoS with Optimal Base Stations (BS)", Wireless Engineering and Technology, vol. 2, pp. 135-145, 2011.

[10] H. Kassim and M. Baba, "Performance Analysis of Fixed and Mobile WiMAX Networks using NCTUns tools". 2011 IEEE Control and System Graduate Research Colloquium. ISSN: 2040-7459, PP. 589-594, November 2011.

[11] R. K. Jha, A. V. Wankhede and U. D. Dalal, "A Survey of Mobile WiMAX IEEE $802.16 \mathrm{~m}$," International Journal of Computer Science and Information Security, Vol. 8, No. 1, pp. 125-131,2010. 